\title{
Transcranial Magnetic Stimulation for the Assessment of Neurodegenerative Disease
}

\author{
Steve Vucic $^{1}$ - Matthew C. Kiernan ${ }^{2}$
}

Published online: 9 November 2016

(C) The American Society for Experimental NeuroTherapeutics, Inc. 2016

\begin{abstract}
Transcranial magnetic stimulation (TMS) is a noninvasive technique that has provided important information about cortical function across an array of neurodegenerative disorders, including Alzheimer's disease, frontotemporal dementia, Parkinson's disease, and related extrapyramidal disorders. Application of TMS techniques in neurodegenerative diseases has provided important pathophysiological insights, leading to the development of pathogenic and diagnostic biomarkers that could be used in the clinical setting and therapeutic trials. Abnormalities of TMS outcome measures heralding cortical hyperexcitability, as evidenced by a reduction of short-interval intracortical inhibition and increased in motorevoked potential amplitude, have been consistently identified as early and intrinsic features of amyotrophic lateral sclerosis (ALS), preceding and correlating with the ensuing neurodegeneration. Cortical hyperexcitability appears to form the pathogenic basis of ALS, mediated by trans-synaptic glutamate-mediated excitotoxic mechanisms. As a consequence of these research findings, TMS has been developed as a potential diagnostic biomarker, capable of identifying upper motor neuronal pathology, at earlier stages of the disease process, and thereby aiding in ALS diagnosis. Of further relevance, marked TMS abnormalities have been reported in other neurodegenerative diseases, which have varied from findings in
\end{abstract}

Matthew C. Kiernan

matthew.kiernan@sydney.edu.au

1 Westmead Clinical School, University of Sydney, Sydney, Australia

2 Bushell Chair of Neurology, Brain and Mind Centre, University of Sydney, Camperdown, Australia
ALS. With time and greater utilization by clinicians, TMS outcome measures may prove to be of utility in future therapeutic trial settings across the neurodegenerative disease spectrum, including the monitoring of neuroprotective, stem-cell, and genetic-based strategies, thereby enabling assessment of biological effectiveness at early stages of drug development.

Keywords Amyotrophic lateral sclerosis - frontotemporal dementia $\cdot$ neurodegeneration $\cdot$ short interval intracortical inhibition $\cdot$ transcranial magnetic stimulation

\section{Introduction}

Transcranial magnetic stimulation (TMS), first described by Barker et al. [1] in the mid-1980s, is a noninvasive neurophysiological technique for assessing human motor cortical function. With TMS, the underlying motor cortex is stimulated by an electric current induced by a transient magnetic field, generated in response to the passage of a large current through the stimulating coil located on the patient's scalp [2]. The extent of cortical activation, and thereby generation of cortical outcome measures, is dependent on coil type (circular $v s$ figure of 8), TMS pulse waveform (monophasic vs biphasic), and coil orientation [3]. In addition, the complexity of the motor cortical anatomy, composed of neurons and neuronal networks, which vary in size, function, orientation, and location, may also influence the response of the motor cortex to TMS [4].

Over the last 3 decades, various TMS techniques have been applied across a wide range of neurodegenerative diseases to assess cortical function, and have provided significant pathophysiological insights and being of diagnostic utility [2]. In amyotrophic lateral sclerosis (ALS), TMS techniques have provided vital information on cortical dysfunction, which has been of pathophysiological and diagnostic significance, 
resulting in an earlier diagnosis and identification of novel therapeutic targets [5]. It should be highlighted, however, that most clinical studies no longer just use the "definite" criteria for diagnosing ALS and this should be considered when discussing the TMS as an early diagnostic biomarker for ALS. Similarly, TMS outcome measures have yielded important pathophysiological insights into the mechanisms underlying neurodegenerative disorders characterized by dementias and movement disorders [6]. In this review, we provide an overview of the physiology of TMS outcome measures and cover the key advances in the understanding of pathophysiology and diagnosis in neurodegenerative diseases as heralded by these TMS outcome measures, focusing on the importance of cortical hyperexcitability as a pathogenic and diagnostic biomarker in ALS.

\section{Principles of TMS}

All magnetic stimulators consist of a capacitor, a device for storing charge, which, when discharged, initiates a flow of current through the stimulating coil and thereby generating a magnetic field. This magnetic field, in turn, induces an electric field in a nearby conductor (namely the motor cortex) resulting in neuronal stimulation $[2$, 7]. The position at which the nerve is excited by magnetic stimulation depends on the voltage gradient parallel to the nerve fiber. Given that neural anatomy in the brain is complex, the point of excitation occurs at bends, branch points, or at the axonal hillock, the transition site from cell body to axon [8]. As such, the orientation of neurons relative to the induced electric field is critical in determining the degree of neuronal activation, and thereby influencing the properties of TMS outcome measures.

The physical properties of the stimulating coil can also influence the degree of neural excitation. Specifically, circular coils activate a larger area of the motor cortex, while figure-ofeight coils generate more focal magnetic fields and thereby activate a smaller area of the motor cortex [2, 7, 9]. In addition, the direction of TMS current flow within the motor cortex will also influence the degree of cortical stimulation and the side of stimulation. Specifically, current flowing from a posterior-anterior direction (i.e., inion to nasion) is most effective at stimulating the motor cortex. For a circular coil positioned at the vertex, clockwise current in the coil (viewed from above) preferentially stimulates the right hemisphere [2, 7, 9]. Consequently, consideration of coil type and coil positioning is critical in interpreting the clinical relevance of TMS outcome measures.

Although the precise identity of neural circuits activated by TMS remains to be elucidated [10], it has been determined that TMS stimulates the motor cortex at a depth of 1.5 to $2.1 \mathrm{~cm}$ [11]. Animal studies have suggested that cortical stimulation results in generation of a complex corticomotoneuronal volley composed of direct (D) waves and multiple indirect (I) waves (Fig. 1) [12]. Human studies, utilizing cervical epidural recording techniques, have confirmed the presence of $\mathrm{D}$ and multiple I waves, labeled as I1, I2, I3, and so on, at intervals of 1.5 to $2.5 \mathrm{~ms}[13,14]$. The $\mathrm{D}$ and I waves, through a complex interaction, appear to underlie the generation of TMS parameters.

A number of models have been proposed as a likely explanation for the descending corticomotoneuronal volleys evoked by TMS stimulation, although each model has limitations [15]. The first model suggested that the periodic bombardment of cortical output cells (Betz cell, layer V) by cortical interneurons with fixed temporal characteristics underlies the generation of the evoked D and I waves [16]. An alternative model proposed that I waves were generated by independent chains of interneuronal circuits, each generating a specific I wave [17]. A third model proposed that magnetic stimulation activates of a large population of neurons, leading to repetitive neuronal firing in concert with the intrinsic membrane properties of the activated neuron [18]. More recently, computer simulation studies have proposed a feed-forward model whereby I-wave generation is regulated by the site of interneuronal synapses with Betz cells, such that later I waves are generated by synapses further away from the cell body, while earlier I waves are generated by synapses closer to the soma [19].

Irrespective of the neuronal circuitry underlying the generation of D and I waves, the direction of cortical current flow appears to influence the composition of the descending corticomotoneuronal volley. Specifically, I waves are best elicited by cortical currents directed in a posterior-anterior direction, whereas $\mathrm{D}$ waves are produced preferentially by currents running in a lateral to medial direction [20-24]. This has led some to propose that $\mathrm{D}$ waves represent direct activation of corticospinal axons, perhaps at the axonal hillock, while I-wave generation is likely to be mediated by a complex interaction of cortical excitatory and inhibitory neurons $[4,15]$.

In a clinical setting, various TMS techniques have been utilized to assess the function of cortical output cells (Betz cells) and intracortical neuronal networks within the primary motor cortex (M1), leading to significant advances in the understanding of underlying pathophysiological processes in neurodegenerative diseases such as ALS and resulting in development of novel diagnostic investigations [10]. The assessment of motor cortex and corticospinal tract integrity is best evaluated by the following TMS outcome parameters: motor threshold, motor evoked potential (MEP) amplitude, central motor conduction time (CMCT), cortical silent period (CSP) duration, short interval intracortical inhibition, and intracortical facilitation. 
Fig. 1 Transcranial magnetic stimulation evokes a descending corticospinal volley composed of direct (D) and multiple indirect (I) waves. The resultant motor evoked potential (green curve) is recorded from a target muscle and is a biomarker of upper motor neuron function

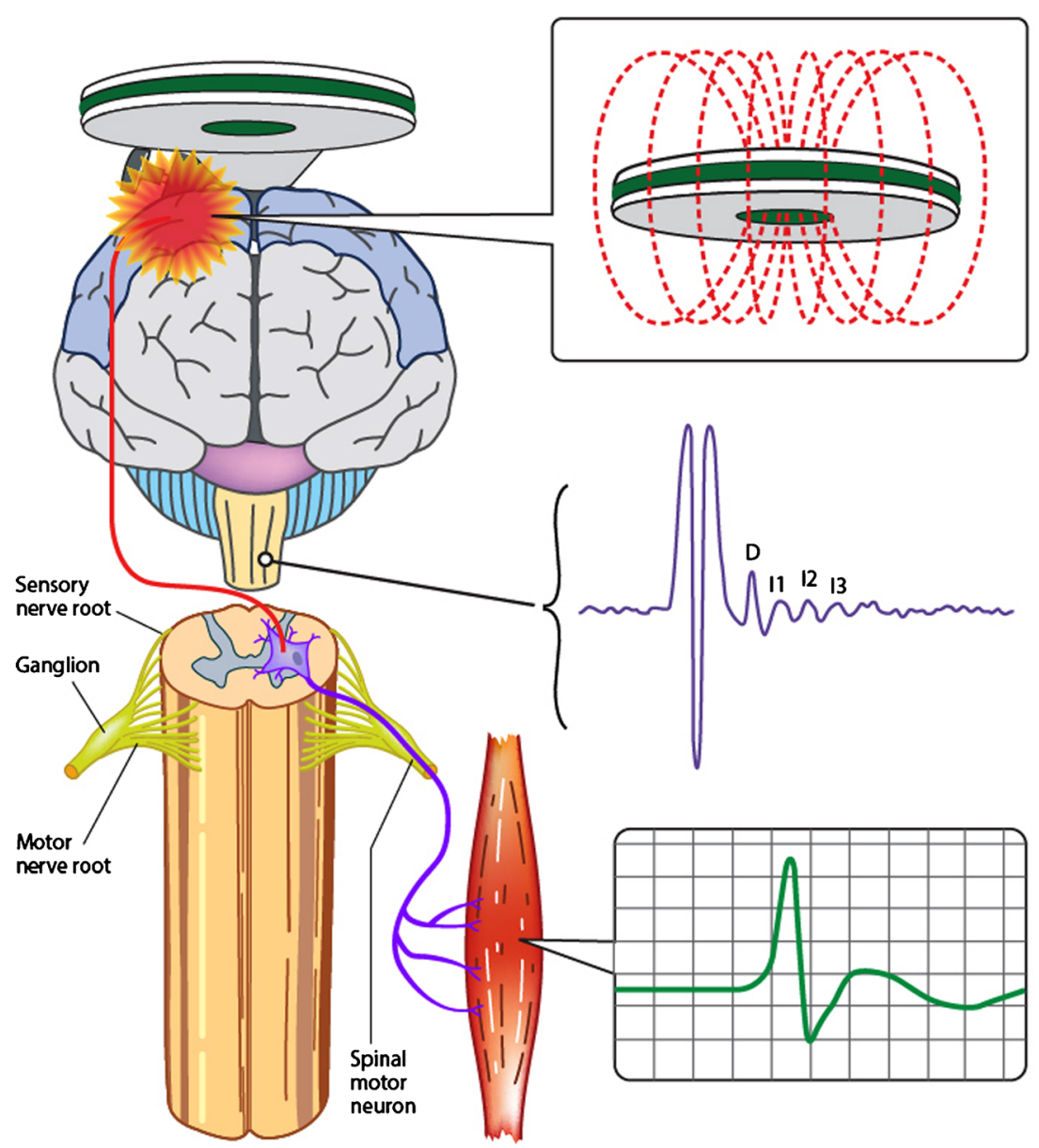

\section{TMS Outcome Measures Utilized} in Neurodegenerative Diseases

\section{Single-Pulse TMS}

Motor threshold (MT) reflects the ease by which motor cortex (M1) output cells and corticomotoneurons are excited. The International Federation of Clinical Neurophysiology has defined motor threshold as the minimum stimulus intensity (\% maximum stimulator output) required to elicit a small MEP response $(>50 \mu \mathrm{V})$ in a target muscle in $50 \%$ of TMS stimulus trials [25]. The development of the threshold-tracking TMS technique has led to a redefinition of MT as the stimulus intensity required to elicit and maintain a target MEP response of $0.2 \mathrm{mV}( \pm 20 \%)[26,27]$. Motor thresholds are believed to reflect the density of corticomotoneuronal projections onto anterior horn cells, whereby MTs appear to be lowest when recorded from the dominant intrinsic hand muscles owing to the highest density of projections [28-30]. In addition, MT also reflect the degree of neuronal membrane excitability of cortical output cells $[11,31,32]$, being modulated by voltagegated $\mathrm{Na}^{+}$channels and the glutamatergic neurotransmitter system [32-35].
MEP amplitude reflects the summation of the descending corticospinal volleys consisting of $\mathrm{D}$ and I waves onto the spinal motor neuron $[16,36]$, delineating the density of corticomotoneuronal projections onto spinal and bulbar motor neurons [37]. At threshold, TMS elicits I waves at intervals of $1.5 \mathrm{~ms}$, which increase in frequency and amplitude with increasing stimulus intensity [36]. This increase in MEP amplitude with increasing stimulus intensity may be utilized to generate a stimulus-response curve [38]. In contrast to MT, the MEP amplitude assesses the function of higher-threshold motor cortex neurons that are positioned further away from the center of the TMS field [2]. Typically, the MEP amplitude is expressed as a percentage of the peripheral maximum compound muscle action potential (CMAP) response [25], thereby accounting for the lower motor neuron contribution and providing insights into the contribution of the upper motor neuron pool to the MEP response. The MEP amplitude exhibits large intersubject variability, limiting the utility of this measure for detecting cortical and corticomotoneuronal abnormalities $[2$, 39].

In addition to corticomotoneuronal density, a host of potentially interacting neurotransmitter systems within the central nervous system appear to also exert modulating effects on 
the MEP response [37, 40]. Specifically, the MEP amplitude is reduced by sodium- and calcium-blocking agents, and by drugs that enhance $\gamma$-aminobutyric acid (GABA)ergic transmission, while agents that enhance glutamatergic and noradrenergic neurotransmission increase the MEP amplitude [2, $32,35]$. It should be stressed, however, that these neuromodulating effects on MEP amplitude occur independently of MT changes, thereby suggesting that different physiological mechanisms underlie the generation of MEP amplitude and MT, and are consequently likely to reflect different cortical output measures.

CMCT refers to the time taken for a neural impulse to traverse the central nervous system and excite the spinal or bulbar motoneurons, reflecting the integrity of the corticospinal tracts [41]. Numerous methods have been utilized to calculate the CMCT, including the F-wave or cervical nerve root stimulation methods [42], although these methods provide an estimation of the central motor conduction time $[7$, 9]. The F-method incorporates the onset latency of the MEP response and subtracts the peripheral conduction time according to the following formula [9]:

Peripheral $\underset{\mathrm{CMCT}}{\stackrel{\text { conduction time }}{\leftrightarrow}}$ MEP latency $-($ minimum $\mathrm{F}$-wave latency + CMAP onset latency-1)/2

where $1 \mathrm{~ms}$ represents to the turnaround time at the spinal motor neuron cell body. The peripheral conduction time value is divided by 2 because the latencies represent the time for the impulse to travel from the peripheral to the cell body and back down to the muscle. The MEP latency refers to the onset latency.

In the cervical nerve root stimulation method, the peripheral nerve conduction time is calculated by recording the CMAP onset latency with electrical or transcranial magnetic nerve root stimulation [43]. As such, the CMCT is calculated according to the following formula:

$\mathrm{CMCT}=\mathrm{MEP}$ onset latency - Cervical nerve root CMAP latency

The CMCT will vary according to the method used for calculation. For example electrical cervical nerve root stimulation will activate the spinal nerve roots closer to the cell body of the spinal motor neuron when compared with magnetic stimulation $[44,45]$.

Multiple factors contribute to the generation of the central motor conduction time, including time to activation of the pyramidal cells, conduction time of the descending volley down the corticospinal tract, synaptic transmission and activation of spinal motor neurons, motor axon conduction, and neuromuscular transmission [9, 41]. A range of technical (neck position during recording), physiological (muscle activity), and anthropometric factors (age, sex, height, limb length, hand dominance) influence central motor conduction time $[9,41]$.
CSP refers to the interruption of voluntary electromyography (EMG) activity within a target muscle following magnetic stimulation of the motor cortex [46], and may be evident with contralateral stimulation of the motor cortex $[2,10]$. The duration of CSP has been defined from the onset of the MEP response to resumption of voluntary EMG activity [37, 46]. Importantly, the duration of CSP correlates with stimulus intensity, but, interestingly, not with the size of the preceding MEP response or the level of background EMG activity [46-48]. It should also be highlighted that the CSP and MEP response exhibit different topographies and thresholds [49], thereby implying that they represent different cortical output properties.

The physiological processes underlying the generation of the CSP are complex, although robustly reflect cortical function [2]. Specifically, CSPs recorded from the contralateral upper limb or cranial muscles are mediated by cortical inhibitory neurons, acting via long-lasting inhibitory postsynaptic potentials through $\mathrm{GABA}_{\mathrm{B}}$ receptors [47, 50-53]. Support for such a mechanism has been provided by pharmacological studies reporting that $\mathrm{GABA}_{\mathrm{B}}$ receptors agonists and $\mathrm{GABA}$ reuptake inhibitors prolong the CSP duration [54, 55]. Separately, the CSP also appears to be influenced by the density of the corticomotoneuronal projections to the spinal motor neuron, with the CSP duration being longest for distal upper limb muscles and shorter for proximal upper and lower limb muscles, as well as facial muscles and the diaphragm [2]. In addition to cortical processes, spinal mechanisms appear to be important in mediating the early part of the CSP in the contralateral limb muscles $[46,47,51]$.

CSP can also be induced by ipsilateral motor cortex stimulation [56]. The ipsilateral CSP probably reflects transcallosal inhibition as it is absent or abnormal in patients with corpus callosum lesions [56, 57]. Separately, noncallosal neural pathways may also generate ipsilateral CSPs [58]. The ipsilateral CSP is assessed by a paired-pulse paradigm whereby a conditioning stimulus is delivered over 1 motor cortex and the test stimulus over the contralateral hemisphere [59]. Interhemispheric inhibition (IHI) occurs at interstimulus intervals (ISI) of between 8 and $50 \mathrm{~ms}$, with 2 prominent phases evident at an ISI of $10 \mathrm{~ms}$ (short-latency IHI) and 40 to $50 \mathrm{~ms}$ (long-latency IHI) [60]. The long-latency IHI appears to be mediated by GABAergic transmission acting via the $\mathrm{GABAB}_{\mathrm{B}}$ receptor system [61].

\section{Paired-Pulse TMS}

The paired-pulse TMS techniques, in which a conditioning stimulus precedes and modulates the effects of a second test stimulus, can provide important insights on the functioning of intracortical inhibitory and excitatory neural circuits and their effect on motor cortex output [2,10]. Two different pairedpulse paradigms, termed the constant stimulus and threshold 
tracking methods, have been developed [27, 62], and both techniques measure short-interval intracortical inhibition (SICI), intracortical facilitation (ICF), and long-interval intracortical inhibition (LICI), all of which reflect cortical function and appear to be important outcome measures in neurodegeneration.

SICI is generated by a paired-pulse paradigm that utilizes a subthreshold conditioning stimulus delivered at predetermined time intervals before a suprathreshold test stimulus [27, 62]. In the first reported paired-pulse TMS paradigm [62-64], the conditioning and test stimuli were kept constant and changes in the test MEP amplitude were assessed. Inhibition was reflected by a reduction in the conditioning test MEP amplitude, compared with the unconditioned test MEP response, when the conditioning-test ISI was set between 1 and $5 \mathrm{~ms}$.

A potential limitation of the "constant stimulus" method pertains to significant MEP amplitude (outcome measure) variability with consecutive stimuli $[65,66]$. The threshold tracking parading was developed in order overcome this potential limitation, whereby a constant target MEP response $(0.2 \mathrm{mV}$ $\pm 20 \%$ ) is tracked by a test stimulus [26, 27, 67]. Inhibition is reflected by higher test stimulus intensity required to generate and maintain the target response, while ICF is the converse.
By selecting a target that lies in the steepest portion of the stimulus response curve, much larger variation in the MEP amplitude translates to smaller variations in the stimulus intensity, the outcome variable (Fig. 2A). Two distinct SICI phases have been consistently identified [26, 27, 68, 69], a smaller phase at ISI $\leq 1 \mathrm{~ms}$ and a larger phase at ISI $3 \mathrm{~ms}$ (Fig. 2B).

The physiological processes underlying the generation of SICI and ICF remain to be fully elucidated, although it is now widely accepted that cortical synpatic mechanisms significantly contribute to the generation of SICI. Specifically, recordings of descending corticospinal volleys cervical epidural electrodes have established an association between SICI and a reduction in the number and amplitude of later I waves (I2 and I3) $[36,63]$. The time course of this I-wave suppression extends up to an ISI of $20 \mathrm{~ms}$, which is the typical duration of the inhibitory postsynaptic potentials mediated through $\mathrm{GABA}_{\mathrm{A}}$ receptors $[65,70]$. Pharmacological studies have underscored the importance of GABAergic neurotransmission, with drugs potentiating $\mathrm{GABA}_{\mathrm{A}}$ receptor transmission increasing SICI [71]. Separately, other neurotransmitter systems also modulate SICI, whereby SICI is increased by antiglutaminergic agents, as well as dopamine agonists and noradrenergic antagonists [32, 72].
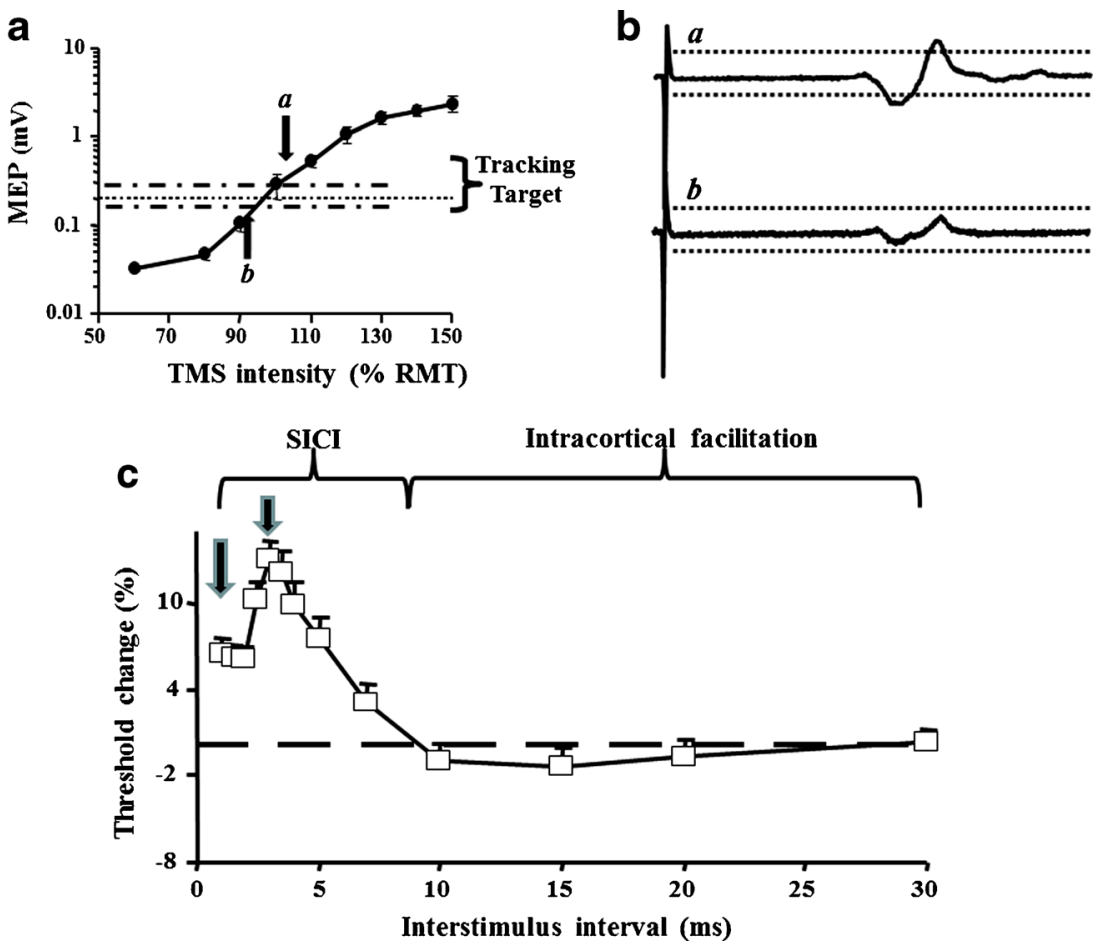

Fig. 2 Threshold-tracking transcranial magnetic stimulation (TMS) technique (A) tracks a magnetic evoked potential (MEP) response of $0.2 \mathrm{mV}$ (tracking target), which lies in the steepest portion of the stimulus response curve. (B) When the MEP amplitude is larger than the tracking target $(a)$ the stimulus intensity is reduced, and conversely when the MEP amplitude is lower than the target $(b)$ the stimulus is reduced. Consequently, inhibition is heralded by higher magnetic stimuli, while facilitation by lower stimuli. By setting the tracking target in the steepest portion of the stimulus-response curve, much larger variations in MEP amplitude translate to smaller variations in the stimulus intensity (the outcome variable). (C) Short-interval intracortical inhibition (SICI) is represented by the stimulus intensity (threshold) being above the zero line (dotted line) and has 2 distinct peaks at interstimulus interval 1 and $3 \mathrm{~ms}$. Intracortical facilitation is heralded by the curve below zero (dotted line). RMT $=$ resting motor threshold 
Although it is now well established that synaptic processes mediate the second phase of SICI [70, 71, 73, 74], the precise mechanisms underlying the first phase of SICI remain uncertain. Refractoriness of cortical axons with resultant resynchronization of corticocortical and corticomotoneuronal volleys was initially postulated as a potential mechanism underlying the first phase of SICI [26, 75]. Subsequent studies have argued about the importance of synaptic processes with the initial phase of SICI possibly driven by cortical inhibitory circuits distinct to those mediating the later SICI phase [68, 76].

$I C F$ is also generated by a paired-pulse paradigm, with the ISI set to between 7 and $30 \mathrm{~ms}$, and is heralded by an increase in the conditioned test MEP amplitude. The physiological processes mediating ICF remain obscure, although it has been argued that neuronal circuits in the motor cortex, which are distinct to those mediating SICI, underlie ICF [29, 71]. Interestingly, ICF was not associated with I-wave amplitude and frequency changes of descending corticomotoneuronal volleys leading to the hypothesis that ICF was mediated by unknown spinal excitability changes or by descending activity not detected by epidural recordings [2]. Intracortical facilitation appears to be mediated by distinct cortical processes to those mediating SICI, which are of higher threshold [64] and antagonized by antiglutaminergic agents [72].

LICI refers to inhibition of a test MEP response when preceded by a suprathreshold conditioning stimulus at an ISI of
50 to $300 \mathrm{~ms}[3,27]$. LICI appears to be a cortical phenomenon mediated by $\mathrm{GABA}_{\mathrm{B}}$ receptors [55]. Different cortical inhibitory circuits appear to mediate LICI, SICI, and the cortical silent period [2]. Interestingly, LICI may inhibit SICI through presynaptic $\mathrm{GABA}_{\mathrm{B}}$ receptors [77].

Short-latency afferent inhibition (SAI) is a paired-pulse paradigm combining peripheral sensory stimuli with TMS, and reflects inhibitory modulation of large sensory fibers on the motor cortex [78]. Specifically, when a median sensory stimulus is delivered $\sim 20 \mathrm{~ms}$ prior to the magnetic pulse, the MEP response is suppressed. Pharmacologic studies have suggested that the SAI reflects central cholinergic activity [32, 79].

\section{TMS Abnormalities in Neurodegenerative Diseases}

The assessment of cortical function in patients with neurodegenerative disease has proved invaluable in the understanding of the underlying pathogenesis. TMS techniques have been clinically applied in a host of neurodegenerative diseases, including ALS, dementias, and movement disorders, leading to development of important pathophysiological, diagnostic, and prognostic outcome measures (Table 1). This section will provide an overview of the importance TMS outcome measures in various neurodegenerative diseases.
Table 1 Summary of abnormalities of transcranial magnetic stimulation (TMS) outcome parameters in neurodegenerative diseases, including amyotrophic lateral sclerosis (ALS), frontotemporal dementia (FTD), Alzheimer's disease (AD), Parkinson's disease (PD), multiple system atrophy (MSA), and Huntington's disease (HD)

\begin{tabular}{|c|c|c|c|c|c|c|c|}
\hline & RMT (\%) & $\begin{array}{l}\text { MEP amplitude } \\
(\%)\end{array}$ & $\begin{array}{l}\text { CMCT } \\
(\mathrm{ms})\end{array}$ & $\begin{array}{l}\text { CSP duration } \\
(\mathrm{ms})\end{array}$ & $\begin{array}{l}\text { SICI } \\
(\%)\end{array}$ & $\begin{array}{l}\mathrm{ICF} \\
(\%)\end{array}$ & $\begin{array}{l}\text { SAI } \\
(\%)\end{array}$ \\
\hline ALS & $\begin{array}{l}\text { Reduced } \\
\text { Increased } \\
\text { Inexcitable }\end{array}$ & $\begin{array}{l}\text { Increased } \\
\text { Normal }\end{array}$ & $\begin{array}{l}\text { Prolonged } \\
\text { Normal }\end{array}$ & Reduced & Reduced & $\begin{array}{l}\text { Increased } \\
\text { Normal }\end{array}$ & Not done \\
\hline FTD & Normal & Absent & Prolonged & Normal & Reduced & Normal & Normal \\
\hline $\mathrm{AD}$ & Reduced & Increased & Normal & Normal & Reduced & Normal & Reduced \\
\hline PD & $\begin{array}{l}\text { Increased } \\
\text { Normal }\end{array}$ & $\begin{array}{l}\text { Normal } \\
\text { Normal }\end{array}$ & Normal & $\begin{array}{l}\text { Reduced } \\
\text { Reduced } \\
\text { Normal }\end{array}$ & $\begin{array}{l}\text { Normal } \\
\text { Reduced } \\
\text { Normal }\end{array}$ & Normal & $\begin{array}{l}\text { Reduced } \\
\text { Prolonged } \\
\text { Normal }\end{array}$ \\
\hline PSP & Normal & Increased & Normal & Reduced & Reduced & Normal & Normal \\
\hline CBD & Increase & Normal & Normal & Reduced & Reduced & Reduced & Not done \\
\hline MSA & $\begin{array}{l}\text { Increased } \\
\text { Normal }\end{array}$ & Normal & Normal & Prolonged & Reduced & Normal & $\begin{array}{l}\text { Reduced } \\
\text { Normal }\end{array}$ \\
\hline HD & Increased & Reduced & Normal & $\begin{array}{l}\text { Prolonged } \\
\text { Reduced }\end{array}$ & Reduced & Increased & Reduced \\
\hline
\end{tabular}

A variety of TMS abnormalities were identified in different neurodegenerative diseases. Importantly, the TMS outcome measures were influenced by stage of disease. For example resting motor threshold (RMT) was reduced in early stages of ALS and AD, but increased in later stages. MEP $=$ motor-evoked potential; $\mathrm{CMCT}=$ central motor conduction time; $\mathrm{CSP}=$ cortical silent period; $\mathrm{SICI}=$ short-interval intracortical inhibition; $\mathrm{ICF}=$ intracortical facilitation; $\mathrm{SAI}=$ short-latency afferent inhibition; $\mathrm{PSP}=$ progressive supranuclear palsy; $\mathrm{CBD}=$ corticobasal degeneration 


\section{ALS}

Unraveling the nature of the relationship between upper and lower motor neuron dysfunction appears to be fundamental to understanding the pathogenesis of ALS [80]. Cortical dysfunction has been postulated to represent a primary event in ALS, mediating lower motor neuron degeneration via a transsynaptic glutaminergic excitotoxic mechanism (the so-called "dying forward hypothesis") [81-84].

TMS studies have provided critical insights into the relationship between upper and lower motor neuron dysfunction, and thereby the underlying pathophysiological mechanisms, highlighting the importance of cortical dysfunction in ALS pathophysiology [10]. Paired-pulse TMS techniques have disclosed a marked reduction or absence of SICI in sporadic ALS cohorts that have been accompanied by an increase in ICF (Fig. 3A), which together are indicative of cortical hyperexcitability [85-89]. Importantly, features of cortical hyperexcitability, as heralded by reduced SICI, occur in the early stages of ALS, precede the clinical and neurophysiological onset of lower motor neuron dysfunction, and correlate with biomarkers of peripheral neurodegeneration $[5,87,90]$.

Of further relevance, reduction of SICI was established to be an early and prominent feature in familial ALS cohorts secondary to mutations in SOD1 [89], FUS [91], and C9orf72 [92] (Fig. 3B). Importantly, the reduction of SICI precedes the clinical onset of superoxide dismutase

a

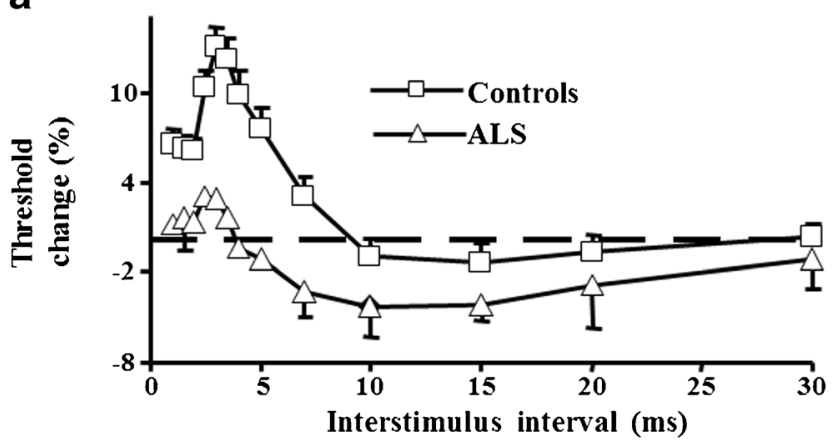

b

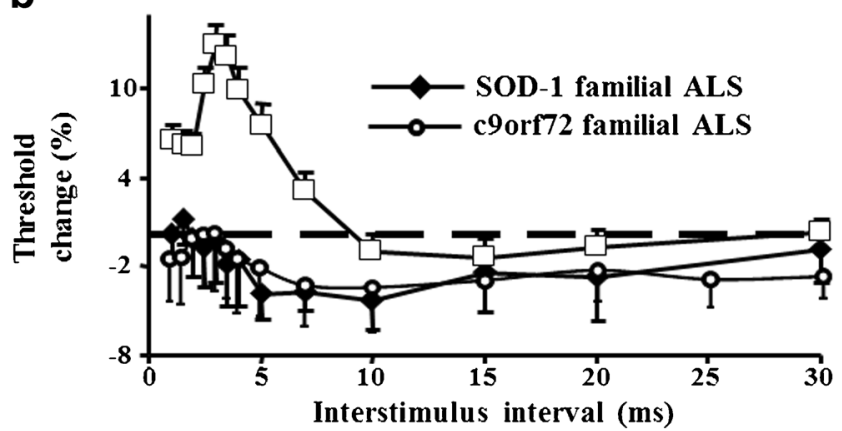

Fig. 3 Short-interval intracortical inhibition is reduced in (A) sporadic amyotrophic lateral sclerosis (ALS) and (B) in familial ALS secondary to mutations in SOD1 and c9orf72
(SOD)-1 related familial ALS by months and correlates with axonal biomarkers of peripheral neurodegeneration [89, 93]. In asymptomatic mutation carriers, SICI appears to be within normal limits, indicative of a normal level of cortical excitability $[89,92]$, and suggesting that factors other than the inheritance of the genetic mutation are important to trigger the disease. Degeneration of inhibitory cortical interneurons along with hyperactivity of cortical excitatory interneurons appears to underlie the reduction of SICI and enhancement of ICF in ALS [94, 95]. Given that seizures can affect TMS parameters [96], patients with ALS with seizure disorders were excluded from the above-discussed studies.

Abnormalities of SICI and ICF have also been observed in atypical ALS phenotypes. Specifically, reduction of SICI and increase in ICF have been reported in the clinically pure lower motor neuron syndrome disorders, flail arm, and flail leg variants of ALS [97, 98]. In addition, SICI abnormalities were also documented in primary lateral sclerosis [99], underscoring the importance of cortical disinhibition and hyperexcitability in ALS pathogenesis.

The notion that SICI reduction represents compensatory changes in response to lower motor neuron degeneration has also been suggested [86]. Given, however, that SICI changes were not evident ALS-mimicking disorders, despite a comparable peripheral disease burden $[5,100]$, would argue against such a notion. Of relevance, the partial normalization of SICI with riluzole [101], an antiglutaminergic agent which exerts modest therapeutic benefits in ALS, lend further credence to the notion for a pathogenic role of cortical hyperexcitability in ALS.

In conjunction with reduction of SICI, abnormalities of transcallosal inhibition have been identified as an early feature of ALS, at times preceding the development of upper motor neuron signs [102, 103]. The impairment of transcallosal inhibition was postulated to underlie the development mirror movements, mediate disease spread [104], and to contribute to the overall cortical hyperexcitability in ALS [103, 105]. Degeneration of inhibitory transcallosal fibers was postulated to mediate a reduction of transcallosal inhibition in ALS [102].

Single-pulse TMS parameters have provided corroborating evidence of the importance of cortical hyperexcitability in ALS pathogenesis [10]. Specifically, longitudinal studies in patients with sporadic ALS have established an initial reduction of motor thresholds (indicative of cortical hyperexcitability), followed by a progressive and eventual cortical inexcitability in later stages of ALS [86, 87, 89, 106-108]. Patients with ALS with profuse fasciculations, exaggerated deep-tendon reflexes, and a preserved muscle exhibit a prominent reduction in MT [109], supporting the notion that cortical hyperexcitability is an early and important pathophysiological process in ALS. 
Significant increases in MEP amplitudes have also been reported in sporadic and familial forms of ALS, as well as atypical ALS phenotypes [10]. Increases in MEP amplitude, representing cortical hyperexcitability, appear to be an early feature in ALS, and correlate with surrogate biomarkers of axonal degeneration such as the strength duration time constant $[87,89,97]$. Importantly, this increase in the MEP amplitude is not evident in mimic disorders, despite a comparable degree of lower motor neuron dysfunction $[5,100]$, thereby reaffirming the importance of excitotoxicity in ALS pathogenesis $[88,100,110]$.

In conjunction with changes in motor threshold and MEP amplitudes, significant reduction in CSP duration has also been identified as an intrinsic and early feature in sporadic and familial ALS cohorts [86-89, 102, 110]. As with other TMS parameters, the reduction of CSP duration appears to be specific feature of ALS, being normal in ALS-mimicking disorders, such as X-linked bulbospinal muscular atrophy (Kennedy's disease), acquired neuromyotonia, and distal hereditary motor neuronopathy with pyramidal features $[88$, 100, 110, 111]. Although the precise mechanisms underlying CSP reduction in ALS remain to be fully elucidated, degeneration or dysfunction of the long-latency cortical inhibitory interneurons acting via $\mathrm{GABA}_{\mathrm{B}}$ receptor system seems like a possible explanation.

Abnormalities of ipsilateral CSP have also been documented as an early feature in ALS, evident in patients lacking upper motor neuron signs $[102,105]$. Given that the ipsilateral CSP is mediated by transcallosal glutamatergic fibers projecting onto inhibitory interneurons in the nonstimulated motor cortex [56], degeneration of these transcallosal fibers or their targeted inhibitory interneurons may account for ipsilateral CSP abnormalities in ALS, thereby further corroborating the importance of cortical dysfunction in ALS pathogenesis.

Of further relevance, modestly prolonged CMCT has also been documented in ALS [108, 112], reflecting degeneration of corticomotoneuronal tracts along with increased desynchronization of descending corticomotoneuronal volleys [107, 113-115]. Abnormalities of CMCT correlated with upper motor neuron signs, and may deteriorate over the course of ALS [116]. The degree of CMCT prolongation is not uniform in different ALS phenotypes, being particularly prominent in the D90A-SOD1-related familial ALS [117]. Importantly, CMCT is especially prolonged when recording from clinically affected regions, such as upper or lower limb muscles in spinal-onset disease (limb-onset), or from cranial muscles in bulbar-onset ALS [9, 118].

\section{Pathogenic Implications}

The TMS measurements provide strong support for the importance of cortical hyperexcitability in ALS pathogenesis, a notion corroborated by genetic, molecular and pathological studies [119]. Specifically, the discovery of the c9orf72 hexanucleotide gene expansion $\left[9 \mathrm{p} 21\left(\mathrm{G}_{4} \mathrm{C}_{2}\right)\right]$ as an important cause of familial $(\sim 40 \%)$ and sporadic $(4.1-8.3 \%)$ ALS, as well as frontotemporal dementia (FTD) [120-122], suggested that ALS and FTD represent an overlapping continuum [123, 124]. Importantly, widespread accumulation of TAR DNAbinding protein 43- and p62-positive inclusions in cortical neurons, a neuropathologic hallmark of $c 90 r f 72$-associated ALS and FTD [125], provided further support for the importance of cortical dysfunction in ALS pathogenesis.

Molecular approaches identifying reductions in expression and function of the astrocytic glutamate transporter, excitatory amino acid transporter 2 (EAAT2), in the SOD-1 mouse model and patients with ALS [126-130], have provided further corroborating evidence for the importance of glutamate excitotoxicity in ALS pathogenesis. Dysfunction of the EAAT2 transporter appears to be a preclinical phenomenon [131, 132], and activation of caspase-3 (an EAAT2 transporter inhibitor) has been reported as a presymptomatic feature in the SOD-1 mouse [131, 132], and increasing EAAT2 transporter expression and activity seems to be neuroprotective [133].

Of further relevance, morphologic and functional cortical neuronal changes, including apical dendritic regressions, loss of dendritic spines, and enhanced glutaminergic excitation, have been documented as either early or presymptomatic abnormalities in mouse models [134-138]. Importantly, these morphological and functional changes result in neuronal hyperexcitability. Separately, motor neurons engineered from pluripotent stem cells collected from patients with ALS exhibit hyperexcitability, and inhibition of this hyperexcitability appears to be neuroprotective [139]. Taken together, these animal studies seem to implicate cortical hyperexcitability as a plausible pathophysiological mechanism in ALS, supporting the abnormal TMS measurements in patients with ALS.

It has been postulated that the cortical hyperexcitability induces motor neuronal degeneration via a glutamatemediated excitotoxic mechanism [81]. For the glutamate hypothesis to be a plausible mechanism in ALS, the issue of vulnerability of motor neurons in patients with ALS, along with sparing of motor neurons in non-ALS conditions exhibiting cortical hyperexcitability [2], must be explained. Importantly, a number of molecular properties of motor neurons in ALS render them prone to glutamate toxicity. Specifically, increased expression of the $\mathrm{Ca}^{2+}$ permeable glutamate receptor, $\alpha$-amino-3-hydroxy-5-methyl-4isoxazoleproprionic acid, has been reported in ALS motor neurons [140, 141], along with aberrant activity of ITPR2, resulting in excessive $\mathrm{Ca}^{2+}$ accumulation upon glutamate stimulation [142], potentially explain the increased sensitivity of ALS motor neurons to glutamate excitotoxicity [143]. Compounding the $\mathrm{Ca}^{2+}$-mediated injury of motor neurons is a deficiency of $\mathrm{Ca}^{2+}$-buffering proteins [144]. Ultimately, a greater influx of $\mathrm{Ca}^{2+}$ ions occurs through excessive 
stimulation of ionotropic glutamate receptors [145, 146], resulting in increased intracellular $\mathrm{Ca}^{2+}$ concentration and activation of $\mathrm{Ca}^{2+}$-dependent enzymatic pathways that mediate neuronal death [147-149]. In addition, glutamate excitotoxicity is associated with increased production of free radicals, leading to further damage of intracellular organelles and neurodegeneration [150-152]. Consequently, abnormalities of TMS measurements, which herald cortical hyperexcitability, are potentially indirectly linked to molecular processes in ALS.

\section{Diagnostic Implications}

The diagnosis of ALS relies on identification of a combination of upper and lower motor neuron signs with disease progression $[153,154]$. Clinically based diagnostic criteria were developed in order to facilitate the diagnosis of ALS $[155,156]$, although in early stages of ALS the sensitivity appears to be limited [157], resulting in significant diagnostic delays. Consequently, institution of appropriate management strategies, such as commencement of neuroprotective therapies, may be critically delayed, and recruitment into clinical trials may occur at later stages in the disease process, perhaps beyond the therapeutic window period [158]. Neurophysiologically based criteria (Awaji criteria) were developed in an attempt to reduce diagnostic delays [154], although the diagnostic benefit appeared most prominent in patients with bulbar-onset disease [159].

A potential limitation of all ALS diagnostic criteria relates to the difficulty in identifying upper motor neuron signs in ALS [160], a vital component of the diagnostic criteria. Underscoring this are findings of suboptimal sensitivity of the Awaji criteria in limb-onset ALS, attributed to clinical assessment of UMN dysfunction [161]. The thresholdtracking TMS technique has identified cortical dysfunction as a robust and early diagnostic biomarker of upper motor neuron dysfunction in ALS [5]. Importantly, reduced SICI $(<5.5 \%)$ reliably differentiated ALS from mimicking disorders (Fig. 4) [90, 100, 162], enabling an earlier diagnosis of ALS by 8 to 15 months when combined with routine clinical and neurophysiological assessment [5, 100]. In addition, identification of subclinical upper motor neuron dysfunction in predominantly lower motor neuron ALS phenotypes, such as the flail arm and flail leg variants, has enabled a more definite diagnosis at an earlier stage in the disease process $[97,98]$. Incorporation of the TMS technique in future ALS diagnostic criteria as an objective tool for assessing upper motor neuron function may hasten ALS diagnosis and thereby enable earlier recruitment into clinical trials, perhaps during the therapeutic window period [158], where neurorecovery therapies may be more effective.

Separately, TMS parameters may be utilized as biomarkers in therapeutic ALS trials. Specifically, partial normalization of

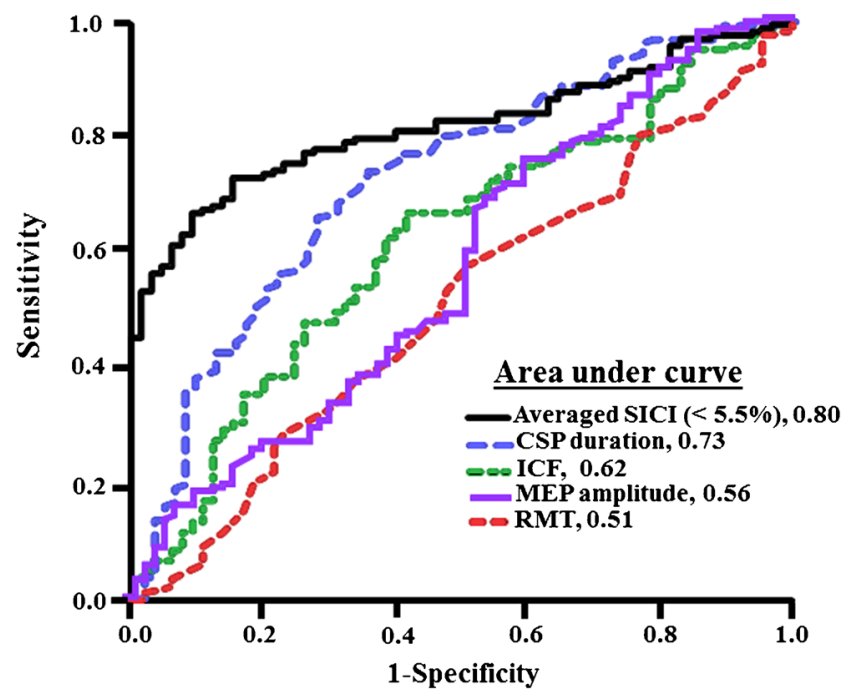

Fig. 4 Receiver-operator characteristic curve disclosed that averaged short-interval intracortical inhibition (SICI; between interstimulus interval 1-7 ms) is the most robust of the transcranial magnetic stimulation (TMS) outcome parameters in differentiating amyotrophic lateral sclerosis from mimicking diseases. Reduction in cortical silent period (CSP) duration is the second most robust biomarker followed by intracortical facilitation (ICF), motor-evoked potential (MEP) amplitude, and resting motor threshold (RMT). Central motor conduction time is least sensitive (not shown). The figure is adapted from [5]

SICI has been documented in sporadic ALS cohorts with riluzole therapy [101], an antiglutaminergic agent that exhibits modest neuroprotective efficacy in ALS [163, 164]. Consequently, assessing the biological effects of future neuroprotective agents on TMS outcome parameters could potentially determine therapeutic efficacy at an early stage of drug development, thereby preventing unnecessary and costly phase III trials [165].

\section{Utility of TMS in Alzheimer's disease}

Alzheimer's disease (AD) is the most frequent of the dementias, characterized by marked short-term memory loss, progressing to disorientation, language deficits, loss of motivation and self-care, behavioral abnormalities, and mood swings [166]. Motor disorders, including gait impairment, rigidity, and hypokinesia, develop in more advanced stages of the disease [6].

TMS studies have reported abnormalities of motor thresholds, which appear to exhibit a bimodal trend [6]. Namely, the motor thresholds appear significantly reduced in early stages of the disease, with an initial threshold reduction paralleling disease progression, despite pharmacological treatment [167-171]. In advanced disease, there is a gradual increase of motor thresholds, probably reflecting the underlying cortical neuronal degeneration [172].

Of further relevance, reduction of SICI in AD has been previously reported $[170,171,173]$, and SICI was increased 
by the cholinesterase inhibitor donepezil [173], suggesting the presence of a functional cholinergic deficit in $\mathrm{AD}$, which could serve as a potential therapeutic target. The reduction of SICI has been an inconsistent finding, with a number of studies reporting a normal level of SICI [174-178]. One study reported a reduction of $\mathrm{LICI}$ in $\mathrm{AD}$, which appeared to be correlated with cognitive deficits [179]. Separately, consistent reduction of SAI has been established in $\mathrm{AD}[6,43,180]$, in keeping with dysfunction of the cholinergic system. Importantly, SAI was restored by administration of anticholinesterase agents, which correlated with long-term clinical outcome [174], thereby suggesting that SAI may be a prognostic biomarker in $\mathrm{AD}$. In contrast, no consistent changes in intracortical facilitation or cortical silent period duration have been reported in $\mathrm{AD}$ [6]. Consequently, the most robust TMS outcome measures in $\mathrm{AD}$ seem to be an increase in cortical excitability, as reflected by reduction of motor thresholds, accompanied by a reduction in SAI, which changes in other TMS outcome measures being less consistent, a finding that likely reflects the complexity of AD pathophysiology.

\section{Frontotemporal dementia (FTD)}

FTD represents a heterogeneous groups of disorders comprising frontotemporal degeneration, semantic dementia, and primary progressive aphasia (PPA) [181]. Clinically, FTD has been characterized by personality and behavioral changes, abnormalities of social conduct, and language and executive cognitive dysfunction [182]. Importantly, FTD and ALS appear to form a disease continuum, a notion underscored by findings that the c9orf72 hexanucleotide expansion is common to both diseases, that $15 \%$ of patients with ALS progress to develop FTD, and that TAR DNA-binding protein 43 inclusion is a characteristic neuropathologic feature in both diseases [120, 121, 124, 125, 181].

TMS studies reported a reduction of SICI in FTD, only evident in patients with PPA, but not in the behavioral variant FTD or semantic dementia [183]. Importantly, the extent of SICI reduction was less when compared with ALS, and was accompanied by a degree lower motor neuron dysfunction, suggesting that secondary spinal motor neuron degeneration may be evident in some FTD phenotypes.

Of further relevance, MEP amplitude was either absent or reduced, while the MEP latency and central motor conduction time were prolonged, with stimulus intensity set to $150 \%$ of resting motor threshold $[6,183]$, indicating dysfunction of the central motor circuits and in keeping with magnetic resonance imaging studies [184]. The MEP abnormalities were only evident in patients with behavioral-variant FTD and semantic dementia, but not in PPA [183]. In contrast to ALS, no abnormalities of motor threshold and CSP duration have been reported in FTD [6]. Taken together, the TMS studies suggest heterogeneity of cortical functional deficits in FTD, implying a complex pathophysiological mechanism in FTD that overlaps with ALS.

\section{Movement Disorders}

Marked TMS abnormalities have been documented in neurodegenerative diseases that are characterized by abnormalities of movement [6]. Specifically, marked reduction of SICI has been reported Parkinson's disease (PD), suggesting impaired intracortical inhibition. Interestingly, the abnormalities of SICI were partially modulated by dopaminergic therapies [185-187]. Others have documented SICI reduction with higher conditioning stimulus intensities, thereby suggesting abnormalities of intracortical facilitatory circuits [188]. In addition, reduction of CSP and ipsilateral CSP duration has been reported in PD, particularly in the early untreated stages of the disease, and correlated with limb rigidity [189]. These TMS abnormalities may reflect the underlying neuropathology, as characterized by widespread cortical thinning on quantitative magnetic resonance imaging testing [190], along with motor cortical metabolic abnormalities secondary to dopamine depletion [191]. Interestingly, some have reported a reduction of SAI in patients with PD that were off medications only [192], and this reduction was only evident in patients with dementia or mild cognitive impairment [193], implying the importance of cholinergic system dysfunction in development of cognitive impairment in PD. In contrast, others have documented either no change [194] or an increase of SAI in PD [195], thereby suggesting a heterogeneity of pathophysiological processes in PD.

Progressive supranuclear palsy (PSP), a potential PD mimicking disorder that is characterized clinically by akinetic rigidity, early gait disturbance, dystonia, and impaired voluntary eye movements [196], exhibits similar TMS abnormalities to that evident in PD. Specifically, reduced SICI, along with abnormalities of contralateral and ipsilateral CSP duration, as well as increased MEP amplitudes have been reported in PSP and appear to correlate with disease progression [197-199]. These TMS findings suggested that disinhibition of the primary motor cortex forms to the pathogenic basis of PSP. Interestingly, the reduction of ipsilateral CSP was predominantly evident in the Richardson's syndrome, and was less prominent in the Parkinsonian form of PSP [199], underscoring the heterogeneity of the underlying pathogenic processes.

Similar to changes in PSP, marked TMS abnormalities have been reported in corticobasal degeneration (CBD) [6], a rare neurodegenerative disorder characterized by asymmetric akinetic hypertonia, unresponsiveness to dopamine, and upper limb apraxia, best described as an alien hand [200]. TMS abnormalities have included an increase of motor thresholds [201], along with reduction of SICI [175] and CSP duration[197], and absence of ipsilateral CSP [197]. These 
TMS changes were shown to correlate with clinical features of CBD such as limb apraxia [201,202], and cognitive disorders [203]. Importantly the TMS changes were associated with structural cortical abnormalities characterized by atrophy of the primary motor and premotor cortices, and thalamus, as well as thinning of the corpus callosum [197, 201]. Consequently, global abnormalities of inhibitory processes, secondary to neurodegeneration within the motor cortices, appear to form the pathogenic basis of CBD.

Multiple system atrophy (MSA), a neurodegenerative disorder characterized by parkinsonism, cerebellar dysfunction, and autonomic failure [6], exhibited similar TMS abnormalities to PSP. Reduction of SICI along with abnormalities of ipsi- and contralateral cortical silent periods and increased motor thresholds, were described in MSA [189, 197, 204], and were evident in both the Parkinsonian and cerebellar forms [204]. The TMS findings, however, were inconsistent, with some reporting no abnormalities of the cortical silent period [205]. Although the pathophysiological processes are likely to be complex, the TMS studies suggest that dysfunction within the corticobasal ganglia-thalamocortical circuits form an important pathogenic basis for MSA.

In Huntington's disease (HD), a hereditary neurodegenerative disorder characterized by the presence of motor, psychiatric, and cognitive symptoms, TMS studies have suggested the importance of cortical excitability [6]. Early cortical dysfunction, characterized by increased motor threshold and reduced SAI, have been described in HD and correlated with motor symptoms [206]. In addition, a significant reduction of ICF has also been reported in early stages of HD, implying that abnormalities of excitatory circuits, acting via ionotropic glutamate receptors, may be important in HD pathogenesis [207]. Reduction of SICI has also been described in HD and correlated with motor symptoms [208], suggesting the importance of GABAergic circuits, in HD pathogenesis.

\section{Conclusion}

Outcome parameters derived from TMS have provided critical insights in the understanding of the underlying pathophysiological processes in neurodegenerative diseases. Specifically, cortical hyperexcitability has been identified as an early feature in sporadic ALS, preceding lower motor neuron dysfunction, and correlating with peripheral neurodegeneration. In addition, TMS techniques have established that cortical hyperexcitability is a presymptomatic feature in familial ALS, thereby strongly supporting a central origin of ALS. In addition, TMS outcome parameters appear to be of diagnostic significance, particularly in ALS, establishing an earlier diagnosis, perhaps within the therapeutic window period. Of further relevance, cortical dysfunction has also been identified in neurodegenerative diseases characterized by dementias or movement disorders, and correlating with clinical features in these neurodegenerative diseases. Importantly, TMS outcome measures seem likely to become incorporated into future diagnostic criteria for neurodegenerative diseases, which may provide clinically meaningful biomarkers for assessing the biological efficacy of therapeutic agents.

Required Author Forms Disclosure forms provided by the authors are available with the online version of this article

\section{References}

1. Barker AT, Jalinous R, Freeston IL. (1985). Non-invasive magnetic stimulation of human motor cortex. Lancet 1, 1106-1107.

2. Chen R, Cros D, Curra A, et al. (2008). The clinical diagnostic utility of transcranial magnetic stimulation: report of an IFCN committee. Clin Neurophysiol 119, 504-532.

3. Rossini PM, Burke D, Chen R, et al. (2015). Non-invasive electrical and magnetic stimulation of the brain, spinal cord, roots and peripheral nerves: basic principles and procedures for routine clinical and research application. An updated report from an I.F.C.N. Committee. Clin Neurophysiol 126, 1071-1107.

4. Di Lazzaro V, Ziemann U, Lemon RN. (2008). State of the art: physiology of transcranial motor cortex stimulation. Brain Stimul $1,345-362$.

5. Menon P, Geevasinga N, Yiannikas C, Howells J, Kiernan MC, Vucic S. (2015). Sensitivity and specificity of threshold tracking transcranial magnetic stimulation for diagnosis of amyotrophic lateral sclerosis: a prospective study. Lancet Neurol 14, 478-484.

6. Cantone M, Di Pino G, Capone F, et al. (2014). The contribution of transcranial magnetic stimulation in the diagnosis and in the management of dementia. Clin Neurophysiol 125, 1509-1532.

7. Rossini PM, Barker AT, Berardelli A, et al. (1994). Non-invasive electrical and magnetic stimulation of the brain, spinal cord and roots: basic principles and procedures for routine clinical application. Report of an IFCN committee. Electroencephalogr Clin Neurophysiol 91, 79-92.

8. Abdeen MA, Stuchly MA. (1994). Modeling of magnetic field stimulation of bent neurons. IEEE Trans Biomed Eng 41, 10921095.

9. Mills K. Magnetic stimulation and central conduction time. Amsterdam: Elsevier B.V.; 2004.

10. Vucic S, Ziemann U, Eisen A, Hallett M, Kiernan MC. (2013). Transcranial magnetic stimulation and amyotrophic lateral sclerosis: pathophysiological insights. J Neurol Neurosurg Psychiatry 84, 1161-1170.

11. Rudiak D, Marg E. (1994). Finding the depth of magnetic brain stimulation: a re-evaluation. Electroencephalogr Clin Neurophysiol 93, 358-371.

12. Patton HD, Amassian VE. (1954). Single and multiple-unit analysis of cortical stage of pyramidal tract activation. J Neurophysiol $17,345-363$

13. Kaneko K, Fuchigami Y, Morita H, Ofuji A, Kawai S. (1997). Effect of coil position and stimulus intensity in transcranial magnetic stimulation on human brain. J Neurol Sci 147, 155-159.

14. Di Lazzaro V, Oliviero A, Profice P, et al. (1998). Comparison of descending volleys evoked by transcranial magnetic and electric stimulation in conscious humans. Electroencephalogr Clin Neurophysiol 109, 397-401.

15. Di Lazzaro V, Profice P, Ranieri F, et al. (2012). I-wave origin and modulation. Brain Stim 5, 512-525. 
16. Amassian VE, Stewart M, Quirk GJ, Rosenthal JL. (1987). Physiological basis of motor effects of a transient stimulus to cerebral cortex. Neurosurgery 20, 74-93.

17. Day BL, Dressler D, Maertens de Noordhout A, et al. (1989). Electric and magnetic stimulation of human motor cortex: surface EMG and single motor unit responses. J Physiol (Lond) 412, 449473.

18. Ziemann U, Rothwell JC. (2000). I-waves in motor cortex. J Clin Neurophysiol 17, 397-405.

19. Rusu CV, Murakami M, Ziemann U, Triesch J. (2014). A model of TMS-induced I-waves in motor cortex. Brain Stimul 7, 401-414.

20. Werhahn KJ, Fong JK, Meyer BU, et al. (1994). The effect of magnetic coil orientation on the latency of surface EMG and single motor unit responses in the first dorsal interosseous muscle. Electroencephalogr Clin Neurophysiol 93, 138-146.

21. Kaneko K, Kawai S, Fuchigami Y, Morita H, Ofuji A. (1996). The effect of current direction induced by transcranial magnetic stimulation on the corticospinal excitability in human brain. Electroencephalogr Clin Neurophysiol 101, 478-482.

22. Sakai K, Ugawa Y, Terao Y, Hanajima R, Furubayashi T, Kanazawa I. (1997). Preferential activation of different I waves by transcranial magnetic stimulation with a figure-of-eight-shaped coil. Exp Brain Res 113, 24-32.

23. Di Lazzaro V, Oliviero A, Mazzone P, et al. (2003). Generation of I waves in the human: spinal recordings. Suppl Clin Neurophysiol $56,143-152$.

24. Di Lazzaro V, Oliviero A, Pilato F, et al. (2003). Corticospinal volleys evoked by transcranial stimulation of the brain in conscious humans. Neurol Res 25, 143-150.

25. Rossini PM, Berardelli A, Deuschl G, et al. (1999). Applications of magnetic cortical stimulation. The International Federation of Clinical Neurophysiology. Electroencephalogr Clin Neurophysiol Suppl 52, 171-185.

26. Fisher RJ, Nakamura Y, Bestmann S, Rothwell JC, Bostock H. (2002). Two phases of intracortical inhibition revealed by transcranial magnetic threshold tracking. Exp Brain Res 143, 240-248.

27. Vucic S, Howells J, Trevillion L, Kiernan MC. (2006). Assessment of cortical excitability using threshold tracking techniques. Muscle Nerve 33, 477-486.

28. Brouwer B, Ashby P. (1990). Corticospinal projections to upper and lower limb spinal motoneurons in man. Electroencephalogr Clin Neurophysiol 76, 509-519.

29. Chen R, Tam A, Butefisch C, et al. (1998). Intracortical inhibition and facilitation in different representations of the human motor cortex. J Neurophysiol 80, 2870-2881.

30. Macdonell RA, Shapiro BE, Chiappa KH, et al. (1991). Hemispheric threshold differences for motor evoked potentials produced by magnetic coil stimulation. Neurology 41, 1441-1444.

31. Epstein CM, Schwartzberg DG, Davey KR, Sudderth DB. (1990). Localizing the site of magnetic brain stimulation in humans. Neurology 40, 666-670.

32. Ziemann U. (2004). TMS and drugs. Clin Neurophysiol $1717-$ 1729.

33. Di Lazzaro V, Oliviero A, Profice P, et al. (2003). Ketamine increases human motor cortex excitability to transcranial magnetic stimulation. J Physiol 547, 485-496.

34. Mavroudakis N, Caroyer JM, Brunko E, Zegers de Beyl D. (1994). Effects of diphenylhydantoin on motor potentials evoked with magnetic stimulation. Electroencephalogr Clin Neurophysiol 93, 428-433.

35. Boroojerdi B, Battaglia F, Muellbacher W, Cohen LG. (2001). Mechanisms influencing stimulus-response properties of the human corticospinal system. Clin Neurophysiol 112, 931-937.

36. Di Lazzaro V, Restuccia D, Oliviero A, et al. (1998). Magnetic transcranial stimulation at intensities below active motor threshold activates intracortical inhibitory circuits. Exp Brain Res 119, 265 268.

37. Ziemann U. Cortical threshold and excitability measurements. In: Eisen A, ed. Clinical Neurophysiology of Motor Neuron Diseases Handbook of Clinical Neurophysiology. Amsterdam: Elsevier; 2004:317-335.

38. Devanne H, Lavoie BA, Capaday C. (1997). Input-output properties and gain changes in the human corticospinal pathway. Exp Brain Res 114, 329-338.

39. Hess CW, Mills KR, Murray NM, Schriefer TN. (1987). Magnetic brain stimulation: central motor conduction studies in multiple sclerosis. Ann Neurol 22, 744-752.

40. Paulus W, Classen J, Cohen LG, et al. (2008). State of the art: Pharmacologic effects on cortical excitability measures tested by transcranial magnetic stimulation. Brain Stimul 1, 151-163.

41. Udupa K, Chen R. (2013). Central motor conduction time. Handb Clin Neurol 116, 375-386.

42. Claus D. (1990). Central motor conduction: method and normal results. Muscle Nerve 13, 1125-1132.

43. Mills KR, Murray NM. (1986). Electrical stimulation over the human vertebral column: which neural elements are excited? Electroencephalogr Clin Neurophysiol 63, 582-589.

44. Vucic S, Cairns KD, Black KR, Chong PS, Cros D. (2006). Cervical nerve root stimulation. Part I: technical aspects and normal data. Clin Neurophysiol 117, 392-397.

45. Cros D, Chiappa KH, Gominak S, et al. (1990). Cervical magnetic stimulation. Neurology 40, 1751-1756.

46. Cantello R, Gianelli M, Civardi C, Mutani R. (1992). Magnetic brain stimulation: the silent period after the motor evoked potential. Neurology 42, 1951-1959.

47. Inghilleri M, Berardelli A, Cruccu G, Manfredi M. (1993). Silent period evoked by transcranial stimulation of the human cortex and cervicomedullary junction. $J$ Physiol (Lond) 466, 521-534.

48. Triggs WJ, Kiers L, Cros D, Fang J, Chiappa KH. (1993). Facilitation of magnetic motor evoked potentials during the cortical stimulation silent period. Neurology 43, 2615-2620.

49. Wassermann EM, Pascual-Leone A, Valls-Sole J, Toro C, Cohen LG, Hallett M. (1993). Topography of the inhibitory and excitatory responses to transcranial magnetic stimulation in a hand muscle. Electroencephalogr Clin Neurophysiol 89, 424-433.

50. Avoli M, Hwa G, Louvel J, Kurcewicz I, Pumain R, Lacaille JC. (1997). Functional and pharmacological properties of GABAmediated inhibition in the human neocortex. Can J Physiol Pharmacol 75, 526-534.

51. Chen R, Lozano AM, Ashby P. (1999). Mechanism of the silent period following transcranial magnetic stimulation. Evidence from epidural recordings. Exp Brain Res 128, 539-542.

52. Ziemann U, Netz J, Szelenyi A, Homberg V. (1993). Spinal and supraspinal mechanisms contribute to the silent period in the contracting soleus muscle after transcranial magnetic stimulation of human motor cortex. Neurosci Lett 156, 167-171.

53. Connors BW, Malenka RC, Silva LR. (1988). Two inhibitory postsynaptic potentials, and GABAA and GABAB receptormediated responses in neocortex of rat and cat. J Physiol 406, 443-468.

54. Siebner HR, Dressnandt J, Auer C, Conrad B. (1998). Continuous intrathecal baclofen infusions induced a marked increase of the transcranially evoked silent period in a patient with generalized dystonia. Muscle Nerve 21, 1209-1212.

55. Werhahn KJ, Kunesch E, Noachtar S, Benecke R, Classen J. (1999). Differential effects on motorcortical inhibition induced by blockade of GABA uptake in humans. $J$ Physiol (Lond) 517, 591-597.

56. Meyer BU, Roricht S, Grafin von Einsiedel H, Kruggel F, Weindl A. (1995). Inhibitory and excitatory interhemispheric transfers 
between motor cortical areas in normal humans and patients with abnormalities of the corpus callosum. Brain 118, 429-440.

57. Wahl M, Hubers A, Lauterbach-Soon B, et al. (2011). Motor callosal disconnection in early relapsing-remitting multiple sclerosis. Hum Brain Mapp 32, 846-855.

58. Compta Y, Valls-Sole J, Valldeoriola F, Kumru H, Rumia J. (2006). The silent period of the thenar muscles to contralateral and ipsilateral deep brain stimulation. Clin Neurophysiol 117, 2512-2520.

59. Ferbert A, Priori A, Rothwell JC, Day BL, Colebatch JG, Marsden CD. (1992). Interhemispheric inhibition of the human motor cortex. J Physiol 453, 525-546.

60. Ni Z, Gunraj C, Nelson AJ, et al. (2009). Two phases of interhemispheric inhibition between motor related cortical areas and the primary motor cortex in human. Cereb Cortex 19, 1654-1665.

61. Irlbacher K, Brocke J, Mechow JV, Brandt SA. (2007). Effects of GABA(A) and GABA(B) agonists on interhemispheric inhibition in man. Clin Neurophysiol 118, 308-316.

62. Kujirai T, Caramia MD, Rothwell JC, et al. (1993). Corticocortical inhibition in human motor cortex. $J$ Physiol (Lond) 471, 501-519.

63. Nakamura H, Kitagawa H, Kawaguchi Y, Tsuji H. (1997). Intracortical facilitation and inhibition after transcranial magnetic stimulation in conscious humans. $J$ Physiol (Lond) 498, 817-823.

64. Ziemann U, Rothwell JC, Ridding MC. (1996). Interaction between intracortical inhibition and facilitation in human motor cortex. J Physiol (Lond) 496, 873-881.

65. Hanajima R, Ugawa Y, Terao Y, et al. (1998). Paired-pulse magnetic stimulation of the human motor cortex: differences among I waves. J Physiol (Lond) 509, 607-618.

66. Kiers L, Cros D, Chiappa KH, Fang J. (1993). Variability of motor potentials evoked by transcranial magnetic stimulation. Electroencephalogr Clin Neurophysiol 89, 415-423.

67. Awiszus F, Feistner H, Urbach D, Bostock H. (1999). Characterisation of paired-pulse transcranial magnetic stimulation conditions yielding intracortical inhibition or I-wave facilitation using a threshold-hunting paradigm. Exp Brain Res 129, 317-324.

68. Vucic S, Cheah BC, Krishnan AV, Burke D, Kiernan MC. (2009). The effects of alterations in conditioning stimulus intensity on short interval intracortical inhibition. Brain Res 39-47.

69. Vucic S, Cheah BC, Krishnan AV, Burke D, Kiernan MC. (2009). The effects of alterations in conditioning stimulus intensity on short interval intracortical inhibition. Brain Res 1273, 39-47.

70. Di Lazzaro V, Oliviero A, Meglio M, et al. (2000). Direct demonstration of the effect of lorazepam on the excitability of the human motor cortex. Clin Neurophysiol 111, 794-799.

71. Ziemann U, Lonnecker S, Steinhoff BJ, Paulus W. (1996). The effect of lorazepam on the motor cortical excitability in man. Exp Brain Res 127-135.

72. Ziemann U, Chen R, Cohen LG, Hallett M. (1998). Dextromethorphan decreases the excitability of the human motor cortex. Neurology 51, 1320-1324.

73. Ilic TV, Meintzschel F, Cleff U, Ruge D, Kessler KR, Ziemann U. (2002). Short-interval paired-pulse inhibition and facilitation of human motor cortex: the dimension of stimulus intensity. $J$ Physiol (Lond) 545, 153-167.

74. Di Lazzaro V, Pilato F, Dileone M, et al. (2006). GABA $A_{A}$ receptor subtype specific enhancement of inhibition in human motor cortex. J Physiol 575, 721-726.

75. Hanajima R, Furubayashi T, Iwata NK, et al. (2003). Further evidence to support different mechanisms underlying intracortical inhibition of the motor cortex. Exp Brain Res 151, 427-434.

76. Roshan L, Paradiso GO, Chen R. (2003). Two phases of shortinterval intracortical inhibition. Exp Brain Res 151, 330-337.

77. Sanger TD, Garg RR, Chen R. (2001). Interactions between two different inhibitory systems in the human motor cortex. $J$ Physiol 530, 307-317.
78. Tokimura H, Di Lazzaro V, Tokimura Y, et al. (2000). Short latency inhibition of human hand motor cortex by somatosensory input from the hand. $J$ Physiol $523 \mathrm{Pt} 2,503-513$.

79. Di Lazzaro V, Oliviero A, Profice P, et al. (2000). Muscarinic receptor blockade has differential effects on the excitability of intracortical circuits in the human motor cortex. Exp Brain Res 135, 455-461.

80. Kiernan MC, Vucic S, Cheah BC, et al. (2011). Amyotrophic lateral sclerosis. Lancet 377, 942-955.

81. Eisen A, Kim S, Pant B. (1992). Amyotrophic lateral sclerosis (ALS): a phylogenetic disease of the corticomotoneuron? Muscle Nerve 15, 219-224.

82. Williamson TL, Cleveland DW. (1999). Slowing of axonal transport is a very early event in the toxicity of ALS-linked SOD1 mutants to motor neurons. Nat Neurosci 2, 50-56.

83. Fischer LR, Culver DG, Tennant P, et al. (2004). Amyotrophic lateral sclerosis is a distal axonopathy: evidence in mice and man. Exp Neurol 185, 232-240.

84. Ravits J, Paul P, Jorg C. (2007). Focality of upper and lower motor neuron degeneration at the clinical onset of ALS. Neurology 68 , 1571-1575.

85. Stefan K, Kunesch E, Benecke R, Classen J. (2001). Effects of riluzole on cortical excitability in patients with amyotrophic lateral sclerosis. Ann Neurol 49, 536-539.

86. Zanette G, Tamburin S, Manganotti P, Refatti N, Forgione A, Rizzuto N. (2002). Different mechanisms contribute to motor cortex hyperexcitability in amyotrophic lateral sclerosis. Clin Neurophysiol 113, 1688-1697.

87. Vucic S, Kiernan MC. (2006). Novel threshold tracking techniques suggest that cortical hyperexcitability is an early feature of motor neuron disease. Brain 129, 2436-2446.

88. Vucic S, Kiernan MC. (2008). Cortical excitability testing distinguishes Kennedy's disease from amyotrophic lateral sclerosis. Clin Neurophysiol 119, 1088-1096.

89. Vucic S, Nicholson GA, Kiernan MC. (2008). Cortical hyperexcitability may precede the onset of familial amyotrophic lateral sclerosis. Brain 131, 1540-1550.

90. Menon P, Kiernan MC, Vucic S. (2015). Cortical hyperexcitability precedes lower motor neuron dysfunction in ALS. Clin Neurophysiol 126, 803-809.

91. Williams KL, Fifita JA, Vucic S, et al. (2013). Pathophysiological insights into ALS with C9ORF72 expansions. J Neurol Neurosurg Psychiatry 84:931-935.

92. Geevasinga N, Menon P, Nicholson GA, et al. (2015). Cortical Function in Asymptomatic Carriers and Patients With C9orf72 Amyotrophic Lateral Sclerosis. JAMA Neurol 72:1268-1274.

93. Vucic S, Kiernan MC. (2010). Upregulation of persistent sodium conductances in familial ALS. J Neurol Neurosurg Psychiatry 81, 222-227.

94. Nihei K, McKee AC, Kowall NW. (1993). Patterns of neuronal degeneration in the motor cortex of amyotrophic lateral sclerosis patients. Acta Neuropathol 86, 55-64.

95. Zhang W, Zhang L, Liang B, et al. (2016). Hyperactive somatostatin interneurons contribute to excitotoxicity in neurodegenerative disorders. Nat Neurosci 19, 557-559.

96. Kimiskidis VK, Valentin A, Kalviainen R. (2014). Transcranial magnetic stimulation for the diagnosis and treatment of epilepsy. Curr Opin Neurol 27, 236-241.

97. Vucic S, Kiernan MC. (2007). Abnormalities in cortical and peripheral excitability in flail arm variant amyotrophic lateral sclerosis. J Neurol Neurosurg Psychiatry 78, 849-852.

98. Menon P, Geevasinga N, Yiannikas C, Kiernan MC, Vucic S. (2016). Cortical contributions to the flail leg syndrome: Pathophysiological insights. Amyotroph Lateral Scler Frontotemporal Degener 17, 389-396. 
99. Geevasinga N, Menon P, Sue CM, et al. (2015). Cortical excitability changes distinguish the motor neuron disease phenotypes from hereditary spastic paraplegia. Eur J Neurol 22, 826-831.

100. Vucic S, Cheah BC, Yiannikas C, Kiernan MC. (2011). Cortical excitability distinguishes ALS from mimic disorders. Clin Neurophysiol 122, 1860-1866.

101. Vucic S, Lin CS-Y, Cheah BC, et al. (2013). Riluzole exerts central and peripheral modulating effects in amyotrophic lateral sclerosis. Brain 136, 1361-1370.

102. Wittstock M, Wolters A, Benecke R. (2007). Transcallosal inhibition in amyotrophic lateral sclerosis. Clin Neurophysiol 118, 301307.

103. Karandreas N, Papadopoulou M, Kokotis P, Papapostolou A, Tsivgoulis G, Zambelis T. (2007). Impaired interhemispheric inhibition in amyotrophic lateral sclerosis. Amyotroph Lateral Scler $8,112-118$

104. Devine MS, Kiernan MC, Heggie S, McCombe PA, Henderson RD. (2014). Study of motor asymmetry in ALS indicates an effect of limb dominance on onset and spread of weakness, and an important role for upper motor neurons. Amyotroph Lateral Scler Frontotemporal Degener 15, 481-487.

105. Wittstock M, Meister S, Walter U, Benecke R, Wolters A. (2011). Mirror movements in amyotrophic lateral sclerosis. Amyotroph Lateral Scler 12, 393-397.

106. Caramia MD, Cicinelli P, Paradiso C, et al. (1991). 'Excitability changes of muscular responses to magnetic brain stimulation in patients with central motor disorders. Electroencephalogr Clin Neurophysiol 81, 243-250.

107. Kohara N, Kaji R, Kojima Y, et al. (1996). Abnormal excitability of the corticospinal pathway in patients with amyotrophic lateral sclerosis: a single motor unit study using transcranial magnetic stimulation. Electroencephalogr Clin Neurophysiol 101, 32-41.

108. Mills KR, Nithi KA. (1997). Corticomotor threshold is reduced in early sporadic amyotrophic lateral sclerosis. Muscle Nerve 20, 1137-1141.

109. Eisen A, Weber M. (2001). The motor cortex and amyotrophic lateral sclerosis. Muscle Nerve 24, 564-573.

110. Vucic S, Nicholson GA, Kiernan MC. (2010). Cortical excitability in hereditary motor neuronopathy with pyramidal signs: comparison with ALS. J Neurol Neurosurg Psychiatry 81, 97-100.

111. Vucic S, Cheah BC, Yiannikas C, Vincent A, Kiernan MC. (2010). Corticomotoneuronal function and hyperexcitability in acquired neuromyotonia. Brain 133, 2727-2733.

112. Eisen A, Shytbel W, Murphy K, Hoirch M. (1990). Cortical magnetic stimulation in amyotrophic lateral sclerosis. Muscle Nerve 13, 146-151.

113. Eisen A, Entezari-Taher M, Stewart H. (1996). Cortical projections to spinal motoneurons: changes with aging and amyotrophic lateral sclerosis. Neurology 46, 1396-1404.

114. Komissarow L, Rollnik JD, Bogdanova D, et al. (2004). Triple stimulation technique (TST) in amyotrophic lateral sclerosis. Clin Neurophysiol 115, 356-360.

115. Mills KR. (2003). The natural history of central motor abnormalities in amyotrophic lateral sclerosis. Brain 126, 2558-2566.

116. Floyd AG, Yu QP, Piboolnurak P, et al. (2009). Transcranial magnetic stimulation in ALS: Utility of central motor conduction tests. Neurology 72, 498-504.

117. Turner MR, Osei-Lah AD, Hammers A, et al. (2005). Abnormal cortical excitability in sporadic but not homozygous D90A SOD1 ALS. J Neurol Neurosurg Psychiatry 76, 1279-1285.

118. Urban P, Wicht S, Hopf H. (2001). Sensitivity of transcranial magnetic stimulation of cortico-bulbar vs. cortico-spinal tract involvement in ALS. $J$ Neurol 248, 850-855.

119. Vucic S, Rothstein JD, Kiernan MC. (2014). Advances in treating amyotrophic lateral sclerosis: insights from pathophysiological studies. Trends Neurosci 37, 433-442.
120. Renton Alan E, Majounie E, Waite A, et al. (2011). A Hexanucleotide Repeat Expansion in C9ORF72 Is the Cause of Chromosome 9p21-Linked ALS-FTD. Neuron 72, 257-268.

121. DeJesus-Hernandez M, Mackenzie Ian R, Boeve Bradley F, et al. (2011). Expanded GGGGCC hexanucleotide repeat in noncoding region of c9orf72 causes chromosome 9p-linked FTD and ALS. Neuron 72, 245-256.

122. Majounie E, Renton AE, Mok K, et al. (2012). Frequency of the C9orf72 hexanucleotide repeat expansion in patients with amyotrophic lateral sclerosis and frontotemporal dementia: a crosssectional study. Lancet Neurol 11, 323-330.

123. Lillo P, Hodges JR. (2009). Frontotemporal dementia and motor neurone disease: overlapping clinic-pathological disorders. $J$ Clin Neurosci 16, 1131-1135.

124. Neumann M, Sampathu DM, Kwong LK, et al. (2006). Ubiquitinated TDP-43 in frontotemporal lobar degeneration and amyotrophic lateral sclerosis. Science 314, 130-133.

125. Al-Sarraj S, King A, Troakes C, et al. (2011). P62 positive, TDP43 negative, neuronal cytoplasmic and intranuclear inclusions in the cerebellum and hippocampus define the pathology of C9orf72linked FTLD and MND/ALS. Acta Neuropathol 122, 691-702.

126. Boillee S, Vande Velde C, Cleveland DW. (2006). ALS: a disease of motor neurons and their nonneuronal neighbors. Neuron 52, 3959.

127. Ionov ID. (2007). Survey of ALS-associated factors potentially promoting $\mathrm{Ca}(2+)$ overload of motor neurons. Amyotroph Lateral Scler 8, 260-265.

128. Rothstein JD, Jin L, Dykes-Hoberg M, Kuncl RW. (1993). Chronic inhibition of glutamate uptake produces a model of slow neurotoxicity. Proc Natl Acad Sci U S A 90, 6591-6595.

129. Rothstein JD, Van Kammen M, Levey AI, Martin LJ, Kuncl RW. (1995). Selective loss of glial glutamate transporter GLT-1 in amyotrophic lateral sclerosis. Ann Neurol 38, 73-84.

130. Trotti D, Rolfs A, Danbolt NC, Brown RH, Jr., Hediger MA. (1999). SOD1 mutants linked to amyotrophic lateral sclerosis selectively inactivate a glial glutamate transporter. Nat Neurosci 2, 848.

131. Boston-Howes W, Gibb SL, Williams EO, Pasinelli P, Brown RH, Jr., Trotti D. (2006). Caspase-3 cleaves and inactivates the glutamate transporter EAAT2. J Biol Chem 281, 14076-14084.

132. Gibb SL, Boston-Howes W, Lavina ZS, et al. (2007). A caspase-3cleaved fragment of the glial glutamate transporter EAAT2 is sumoylated and targeted to promyelocytic leukemia nuclear bodies in mutant SOD1-linked amyotrophic lateral sclerosis. $J$ Biol Chem 282, 32480-32490.

133. Rothstein JD, Patel S, Regan MR, et al. (2005). Beta-lactam antibiotics offer neuroprotection by increasing glutamate transporter expression. Nature 433, 73-77.

134. Pieri M, Carunchio I, Curcio L, Mercuri NB, Zona C. (2009). Increased persistent sodium current determines cortical hyperexcitability in a genetic model of amyotrophic lateral sclerosis. Exp Neurol 215, 368-379.

135. Saba L, Viscomi MT, Caioli S, et al. Altered functionality, morphology, and vesicular glutamate transporter expression of cortical motor neurons from a presymptomatic mouse model of amyotrophic lateral sclerosis. Cereb Cortex 2016;26:1512-1528.

136. Jara JH, Villa SR, Khan NA, Bohn MC, Ozdinler PH. (2012). AAV2 mediated retrograde transduction of corticospinal motor neurons reveals initial and selective apical dendrite degeneration in ALS. Neurobiol Dis 47, 174-183.

137. Kuo JJ, Siddique T, Fu R, Heckman CJ. (2005). Increased persistent $\mathrm{Na}(+)$ current and its effect on excitability in motoneurones cultured from mutant SOD1 mice. J Physiol (Lond) 563, 843-854.

138. Ozdinler PH, Benn S, Yamamoto TH, Guzel M, Brown RH, Jr., Macklis JD. (2011). Corticospinal motor neurons and related subcerebral projection neurons undergo early and specific 
neurodegeneration in hSOD1G(9)(3)A transgenic ALS mice. $J$ Neurosci 31, 4166-4177.

139. Wainger Brian J, Kiskinis E, Mellin C, et al. (2014). Intrinsic membrane hyperexcitability of amyotrophic lateral sclerosis patient-derived motor neurons. Cell Rep 7, 1-11.

140. Kwak S, Kawahara Y. (2005). Deficient RNA editing of GluR2 and neuronal death in amyotropic lateral sclerosis. J Mol Med 83, 110-120.

141. Van Damme P, Braeken D, Callewaert G, Robberecht W, Van Den Bosch L. (2005). GluR2 deficiency accelerates motor neuron degeneration in a mouse model of amyotrophic lateral sclerosis. $J$ Neuropathol Exp Neurol 64, 605-612.

142. van Es MA, Van Vught PW, Blauw HM, et al. (2007). ITPR2 as a susceptibility gene in sporadic amyotrophic lateral sclerosis: a genome-wide association study. Lancet Neurol 6, 869-877.

143. Heath PR, Shaw PJ. (2002). Update on the glutamatergic neurotransmitter system and the role of excitotoxicity in amyotrophic lateral sclerosis. Muscle Nerve 26, 438-458.

144. Ince P, Stout N, Shaw P, et al. (1993). Parvalbumin and calbindin D-28k in the human motor system and in motor neuron disease. Neuropathol Appl Neurobiol 19, 291-299.

145. Choi DW. (1987). Ionic dependence of glutamate neurotoxicity. $J$ Neurosci 7, 369-379.

146. Miller RJ, Murphy SN, Glaum SR. (1989). Neuronal $\mathrm{Ca}^{2+}$ channels and their regulation by excitatory amino acids. Ann N Y Acad Sci 568, 149-158.

147. Meldrum B, Garthwaite J. (1990). Excitatory amino acid neurotoxicity and neurodegenerative disease. Trends Pharmacol Sci 11, 379-387.

148. Regan RF, Panter SS, Witz A, Tilly JL, Giffard RG. (1995). Ultrastructure of excitotoxic neuronal death in murine cortical culture. Brain Res 705, 188-198.

149. Shaw P, Kuncl R. Current concepts in the pathogenesis of ALS. In: WR K, ed. Motor Neuron Disease. Lodon: WB Saunders; 2002: 37-73.

150. Bondy SC, Lee DK. (1993). Oxidative stress induced by glutamate receptor agonists. Brain Res 610, 229-233.

151. Lees GJ. (1993). Contributory mechanisms in the causation of neurodegenerative disorders. Neuroscience 54, 287-322.

152. Maher P, Davis JB. (1996). The role of monoamine metabolism in oxidative glutamate toxicity. J Neurosci 16, 6394-6401.

153. Brooks BR, Miller RG, Swash M, Munsat TL. (2000). El Escorial revisited: revised criteria for the diagnosis of amyotrophic lateral sclerosis. Amyotroph Lateral Scler 1, 293-299.

154. de Carvalho M, Dengler R, Eisen A, et al. (2008). Electrodiagnostic criteria for diagnosis of ALS. Clin Neurophysiol 119, 497-503.

155. Brooks B. (1994). El Escorial World Federation of Neurology criteria for the diagnosis of amyotrophic lateral sclerosis. Subcommittee on Motor Neuron Diseases/Amyotrophic Lateral Sclerosis of the World Federation of Neurology Research Group on Neuromuscular Diseases and the El Escorial "Clinical limits of amyotrophic lateral sclerosis" workshop contributors. J Neurol Sci 124, 96-107.

156. Brooks B, Miller R, Swash M, Munsat T. (2000). El Escorial revisited: revised criteria for the diagnosis of amyotrophic lateral sclerosis. Amyotroph Lateral Scler Other Motor Neuron Disord 1, 293-299.

157. Turner MR, Kiernan MC, Leigh PN, Talbot K. (2009). Biomarkers in amyotrophic lateral sclerosis. Lancet Neurol 8, 94-109.

158. Eisen A, Kiernan M, Mitsumoto H, Swash M. (2014). Amyotrophic lateral sclerosis: a long preclinical period? $J$ Neurol Neurosurg Psychiatry 85, 1232-1238.
159. Costa J, Swash M, de Carvalho M. (2012). Awaji criteria for the diagnosis of amyotrophic lateral sclerosis:a systematic review. Arch Neurol 69, 1410-1416.

160. Swash M. (2012). Why are upper motor neuron signs difficult to elicit in amyotrophic lateral sclerosis? J Neurol Neurosurg Psychiatry 83, 659-662.

161. Higashihara M, Sonoo M, Imafuku I, et al. (2012). Fasciculation potentials in amyotrophic lateral sclerosis and the diagnostic yield of the Awaji algorithm. Muscle Nerve 45, 175-182.

162. Geevasinga N, Menon P, Yiannikas C, Kiernan MC, Vucic S (2014). Diagnostic utility of cortical excitability studies in amyotrophic lateral sclerosis. Eur J Neurol 21, 1451-1457.

163. Lacomblez L, Bensimon G, Leigh PN, Guillet P, Meininger V. (1996). Dose-ranging study of riluzole in amyotrophic lateral sclerosis. Amyotrophic Lateral Sclerosis/Riluzole Study Group II. Lancet 347, 1425-1431.

164. Bensimon G, Lacomblez L, Meininger V. (1994). A controlled trial of riluzole in amyotrophic lateral sclerosis. ALS/Riluzole Study Group. N Engl J Med 330, 585-591.

165. Aggarwal S, Cudkowicz M. (2008). ALS drug development: reflections from the past and a way forward. Neurotherapeutics 5 , 516-527.

166. Hodges JR. (2013). Alzheimer's disease and the frontotemporal dementias: contributions to clinico-pathological studies, diagnosis, and cognitive neuroscience. J Alzheimers Dis 33(Suppl. 1), S211-S217.

167. Di Lazzaro V, Oliviero A, Pilato F, Saturno E, Dileone M, Tonali PA. (2003). Motor cortex hyperexcitability to transcranial magnetic stimulation in Alzheimer's disease: evidence of impaired glutamatergic neurotransmission? Ann Neurol 53, 824.

168. Alagona G, Ferri R, Pennisi G, et al. (2004). Motor cortex excitability in Alzheimer's disease and in subcortical ischemic vascular dementia. Neurosci Lett 362, 95-98.

169. Ferreri F, Pauri F, Pasqualetti P, Fini R, Dal Forno G, Rossini PM. (2003). Motor cortex excitability in Alzheimer's disease: a transcranial magnetic stimulation study. Ann Neurol 53, 102-108.

170. Hoeppner J, Wegrzyn M, Thome J, et al. (2012). Intra- and intercortical motor excitability in Alzheimer's disease. $J$ Neural Transm (Vienna) 119, 605-612.

171. Martorana A, Stefani A, Palmieri MG, et al. (2008). L-dopa modulates motor cortex excitability in Alzheimer's disease patients. $J$ Neural Transm (Vienna) 115, 1313-1319.

172. Perretti A, Grossi D, Fragassi N, et al. (1996). Evaluation of the motor cortex by magnetic stimulation in patients with Alzheimer disease. J Neurol Sci 135, 31-37.

173. Liepert J, Bar KJ, Meske U, Weiller C. (2001). Motor cortex disinhibition in Alzheimer's disease. Clin Neurophysiol 112, 1436-1441.

174. Di Lazzaro V, Oliviero A, Tonali PA, et al. (2002). Noninvasive in vivo assessment of cholinergic cortical circuits in AD using transcranial magnetic stimulation. Neurology 59, 392-397.

175. Alberici A, Bonato C, Calabria M, et al. (2008). The contribution of TMS to frontotemporal dementia variants. Acta Neurol Scand 118, 275-280.

176. Di Lazzaro V, Oliviero A, Pilato F, et al. (2004). Motor cortex hyperexcitability to transcranial magnetic stimulation in Alzheimer's disease. J Neurol Neurosurg Psychiatry 75, 555-559.

177. Martorana A, Di Lorenzo F, Esposito Z, et al. (2013). Dopamine $\mathrm{D}(2)$-agonist rotigotine effects on cortical excitability and central cholinergic transmission in Alzheimer's disease patients. Neuropharmacology 64, 108-113.

178. Nardone R, Bratti A, Tezzon F. (2006). Motor cortex inhibitory circuits in dementia with Lewy bodies and in Alzheimer's disease. J Neural Transm (Vienna) 113, 1679-1684. 
179. Brem AK, Atkinson NJ, Seligson EE, Pascual-Leone A. (2013). Differential pharmacological effects on brain reactivity and plasticity in Alzheimer's disease. Front Psychiatry 4, 124.

180. Nardone R, Bergmann J, Kronbichler M, et al. (2008). Abnormal short latency afferent inhibition in early Alzheimer's disease: a transcranial magnetic demonstration. J Neural Transm (Vienna) $115,1557-1562$.

181. Burrell JR, Halliday GM, Kril JJ, et al. The frontotemporal dementiamotor neuron disease continuum. Lancet 2016;388:919-931.

182. Ahmed RM, Irish M, Piguet O, et al. (2016). Amyotrophic lateral sclerosis and frontotemporal dementia: distinct and overlapping changes in eating behaviour and metabolism. Lancet Neurol 15, 332-342.

183. Burrell JR, Kiernan MC, Vucic S, Hodges JR. (2011). Motor neuron dysfunction in frontotemporal dementia. Brain 134, 25822594.

184. Lillo P, Mioshi E, Burrell JR, Kiernan MC, Hodges JR, Hornberger M. (2012). Grey and white matter changes across the amyotrophic lateral sclerosis-frontotemporal dementia continuum. PLOS ONE 7, e43993.

185. Leon-Sarmiento FE, Rizzo-Sierra CV, Bayona EA, Bayona-Prieto J, Doty RL, Bara-Jimenez W. (2013). Novel mechanisms underlying inhibitory and facilitatory transcranial magnetic stimulation abnormalities in Parkinson's disease. Arch Med Res 44, 221-228.

186. Ni Z, Bahl N, Gunraj CA, Mazzella F, Chen R. (2013). Increased motor cortical facilitation and decreased inhibition in Parkinson disease. Neurology 80, 1746-1753.

187. Barbin L, Leux C, Sauleau P, et al. (2013). Non-homogeneous effect of levodopa on inhibitory circuits in Parkinson's disease and dyskinesia. Parkinsonism Relat Disord 19, 165-170.

188. MacKinnon CD, Gilley EA, Weis-McNulty A, Simuni T. (2005). Pathways mediating abnormal intracortical inhibition in Parkinson's disease. Ann Neurol 58, 516-524.

189. Morita Y, Osaki Y, Doi Y. (2008). Transcranial magnetic stimulation for differential diagnostics in patients with parkinsonism. Acta Neurol Scand 118, 159-163.

190. Zarei M, Ibarretxe-Bilbao N, Compta Y, et al. (2013). Cortical thinning is associated with disease stages and dementia in Parkinson's disease. J Neurol Neurosurg Psychiatry 84, 875-881.

191. Lindenbach D, Bishop C. (2013). Critical involvement of the motor cortex in the pathophysiology and treatment of Parkinson's disease. Neurosci Biobehav Rev 37, 2737-2750.

192. Sailer A, Molnar GF, Paradiso G, Gunraj CA, Lang AE, Chen R. (2003). Short and long latency afferent inhibition in Parkinson's disease. Brain 126, 1883-1894.

193. Manganelli F, Vitale C, Santangelo G, et al. (2009). Functional involvement of central cholinergic circuits and visual hallucinations in Parkinson's disease. Brain 132, 2350-2355.
194. Celebi O, Temucin CM, Elibol B, Saka E. (2012). Short latency afferent inhibition in Parkinson's disease patients with dementia. Mov Disord 27, 1052-1055.

195. Nardone R, Florio I, Lochner P, Tezzon F. (2005). Cholinergic cortical circuits in Parkinson's disease and in progressive supranuclear palsy: a transcranial magnetic stimulation study. Exp Brain Res 163, 128-131.

196. Ling H. (2016). Clinical Approach to Progressive Supranuclear Palsy. J Mov Disord 9, 3-13.

197. Kuhn AA, Grosse P, Holtz K, Brown P, Meyer BU, Kupsch A. (2004). Patterns of abnormal motor cortex excitability in atypical parkinsonian syndromes. Clin Neurophysiol 115, 1786-1795.

198. Conte A, Belvisi D, Bologna M, et al. (2012). Abnormal cortical synaptic plasticity in primary motor area in progressive supranuclear palsy. Cereb Cortex 22, 693-700.

199. Wittstock M, Pohley I, Walter U, Grossmann A, Benecke R, Wolters A. (2013). Interhemispheric inhibition in different phenotypes of progressive supranuclear palsy. J Neural Transm (Vienna) 120, 453-461.

200. Grijalvo-Perez AM, Litvan I. (2014). Corticobasal degeneration. Semin Neurol 34, 160-173.

201. Burrell JR, Hornberger M, Vucic S, Kiernan MC, Hodges JR. (2014). Apraxia and motor dysfunction in corticobasal syndrome. PLOS ONE 9, e92944.

202. Leiguarda RC, Merello M, Nouzeilles MI, Balej J, Rivero A, Nogués M. (2003). Limb-kinetic apraxia in corticobasal degeneration: Clinical and kinematic features. Mov Disord 18, 49-59.

203. Trompetto C, Buccolieri A, Marchese R, Marinelli L, Michelozzi G, Abbruzzese G. (2003). Impairment of transcallosal inhibition in patients with corticobasal degeneration. Clin Neurophysiol 114, 2181-2187.

204. Suppa A, Marsili L, Di Stasio F, et al. (2014). Primary motor cortex long-term plasticity in multiple system atrophy. Mov Disord 29, 97-104.

205. Wolters A, Classen J, Kunesch E, Grossmann A, Benecke R. (2004). Measurements of transcallosally mediated cortical inhibition for differentiating parkinsonian syndromes. Mov Disord 19 , 518-528.

206. Schippling S, Schneider SA, Bhatia KP, et al. (2009). Abnormal motor cortex excitability in preclinical and very early Huntington's disease. Biol Psychiatry 65, 959-965.

207. Nardone R, Lochner P, Marth R, Ausserer H, Bratti A, Tezzon F. (2007). Abnormal intracortical facilitation in early-stage Huntington's disease. Clin Neurophysiol 118, 1149-1154.

208. Abbruzzese G, Buccolieri A, Marchese R, Trompetto C, Mandich P, Schieppati M. (1997). Intracortical inhibition and facilitation are abnormal in Huntington's disease: a paired magnetic stimulation study. Neurosci Lett 228, 87-90. 